\title{
Editorials
}

\section{Case management and assertive community treatment. What is the difference?}

\author{
TOM BURNS
}

\begin{abstract}
There has been a long-running controversy about the relative benefits of Assertive Community Treatment (ACT) compared to Case Management (CM). Several health care systems have initiated major service overhauls on the basis of published evidence. Yet this evidence has been ambiguous and supports differing interpretations. Research is examined which explores the differences in outcomes reported. It uses a range of approaches, most prominently meta-regression, to test a small range of hypotheses to explain the heterogeneity in outcomes. The main determinant of differences between ACT and CM studies is the local bed management procedures and occupancy practice. Those organizational aspects of ACT which are generally shared by CM teams are associated with reduced hospital care but the stringent staffing proposed for ACT does not affect it. ACT is a specialized form of $\mathrm{CM}$, not a categorically different approach. The benefits of introducing it will depend on the nature of current local practice. Important lessons about the need to focus on treatments rather than structures seem not to have been learnt. Psychiatry's recent excessive focus on service structures may have had unintended consequences for our professional identity.
\end{abstract}

\section{RESEARCHING AN EVOLVING PROCESS}

Community mental health practice is characterized by constant change and development. Unconstrained by the need for massive capital investment and buildings, services evolve and diverge, often in an unrecognized and unremarked manner. The National Services Framework for Mental Health Services in the UK prescribed in extensive detail how Assertive Community Treatment Teams (renamed Assertive Outreach (AO) Teams) should be configured and operated (Department of Health, 2001). Yet within two years of their establishment London AO teams displayed recognizably different approaches (Wright et al., 2003). Community psychiatry research is forced to impose a degree of rigidity on evolving practice when conducting trials to determine their outcomes. This freeze-framing of a dynamic process is essential if rigorous trials of interventions that can be reliably described are to be conducted (Burns et al., 1999). Clinicians often complain about these constraints but without them their limited generalisability is well recognized (Coid, 1994).

Address for correspondence: Professor T. Burns, University of Oxford, Warneford Hospital, Oxford OX3 7JX (United Kingdom).

E-mail: tom.burns@psych.ox.ac.uk

Declaration of Interest: None.
For researchers and policy makers there are other consequences of this snapshot approach. First they convey a much more static picture than is really the case. Responding to a follow-up questionnaire 55 out of 92 trialists confirmed that over half of experimental services were no longer in operation and 10 had ceased to operate even before the study was published (Wright et al., 2004). Perhaps a more serious consequence is that the freezing exaggerates the differences between approaches and implies that they are distinct categories rather than, as may be the case, variants on a continuum. Nomenclature can consolidate this exaggeration. Assertive Community Treatment (ACT) is understood to be a successful evidence-based approach that reduces the need for inpatient care. However none of the three most influential trials of ACT (Hoult et al., 1984; Rosenheck et al., 1995; Stein \& Test 1980) called their services ACT at the time but were rebadged as such as ACT became established.

\section{EVOLUTION OF CASE MANAGEMENT}

An even greater challenge is how case management has rapidly evolved since it was first introduced (Intagliata, 1982) to co-ordinate care of the severely mentally ill discharged from closing mental hospitals. The distinction between ACT and early 'brokerage' case management is unproblematic; brokerage case managers were not mental health professionals, did not provide any 
direct care and worked independently. However brokerage case management was rapidly abandoned in favour of clinical case management (Holloway et al., 1995). Unfortunately neither the timing of this change nor the evolution of case management into teams is clearly identifiable. In Europe case managers invariably have been members of multidisciplinary mental health teams (Burns, 1996; Burns et al., 2001). The prevailing European view has been that $\mathrm{ACT}$ is a specialized type of case management team and this is reflected in the use of the term Intensive Case Management (ICM).

The importance of this distinction was clearest with Marshall and Lockwood's two influential meta-analyses of ACT and of CM (Marshall et al., 2001; Marshall \& Lockwood, 1998). In some of the later studies the comparator service for ACT may have been indistinguishable from some of the experimental services in the CM review and, indeed, may have been more like the experimental than comparator service in the earlier ACT studies. This overlap and variation led Catty and colleagues to ignore the labels used by researchers about their services and conduct a systematic review of all home based services which aimed to reduce or substitute inpatient care for severe mental illnesses (Catty et al., 2002).

\section{THE FADING OF ACT SUPERIORITY}

Whether or not there is a major difference between ACT and CM is no longer simply an academic issue. That ACT was associated with reduced hospitalization and CM was not in the Marshall and Lockwood meta-analyses has led to policy decisions to establish ACT teams in several countries. Often this has meant redeploying staff from their current roles which might, or might not, have been quite similar (i.e. many services may have already been organized as different forms of case management teams). The disruption was justified by the potential savings in inpatient care and costs.

A series of European studies of ICM appeared in the 1990 s which cast doubt on the anticipated reduction in inpatient care. Similar results were published in the US also although less commented upon (e.g. Drake et al., 1998). The two most influential of these European studies were the PRiSM study at the Maudsley Hospital in London (Thornicroft et al., 1998) and the multi-centre UK700 trial (Burns et al., 1999). Neither found any reduction in hospitalization and the UK700 trial was sufficiently powered and rigorous to be able to confirm that there was no reduction. Despite protests about the conduct of these trials (Gournay \& Thornicroft, 2000; Sashidharan et al., 1999) there was no evidence of methodological flaws nor, in the case of the UK700 trial, of any failure of model fidelity in the service provision (Fiander et al., 2003).

The last decade has experienced a falling off in the number of ACT trials and failed to provide any highquality trials demonstrating a clear superiority in reducing inpatient care. A five-year review of the introduction of 252 Assertive Outreach Teams in the UK acknowledges that there has been no overall impact on bed occupancy (Glover et al., 2006). The reduction in number of trials reflects in part a decreased interest in the question but also, in part, a publication bias; many small trials have been conducted but in the absence of positive results have been rejected by journals. Some trialists have emphasized better engagement, or patient satisfaction as alternative outcomes in the absence of reduction in inpatient care (Killaspy et al., 2006; Petersen et al., 2005).

\section{TRANSCENDING LABELS: WHAT ACTUALLY GOES ON?}

Two model fidelity scales have been developed and are regularly used for measuring implementation of ACT - the 'IFACT' (McGrew et al., 1994) and the 'DACT' (McGrew et al., 1994). Both are derived from expert opinion and measure closeness to the original Madison service (Stein \& Test 1980); they reflect the thinking of what 'should' characterize good ACT rather than what is known to do so. Model fidelity has been shown to have some association with outcome, albeit not a very strong one. This association has regularly been quoted to confirm the necessity of each of the components of the model to achieve good outcomes.

There are at least three reasons for caution with this assumption. Firstly, good model fidelity has been shown in psychotherapy research to be a powerful indicator of quality in itself. It has a positive association with outcome independent of the efficacy of the therapy. Practitioners of quite different therapies who follow their model closely achieve better outcomes than those who do not even if there is no evidence that the specific therapies have advantages over one another. Good model fidelity may simply be an indicator of more conscientious practitioners rather than a confirmation of the value of the approach. Secondly, published associations are for the total score and this gives little indication of contribution of any specific aspects of the service. Thirdly, there is strong anecdotal evidence of lack of accuracy or objectivity in self-declaration by teams. High model fidelity scores may be necessary for funding and practitioners may report what they believe they ought to do rather than 
what they actually do (e.g. overestimate contact frequencies, exaggerate the level of 24 -hour cover, etc).

Operationalised practice features of home-based care services reported by researchers suggest a more modest number of core features (figure 1) that cluster in both case management and ACT services (Wright et al., 2004). This same study found a high rate of early modification of experimental services which indicates that some of the more demanding features of ACT practice are abandoned soon after studies are completed.

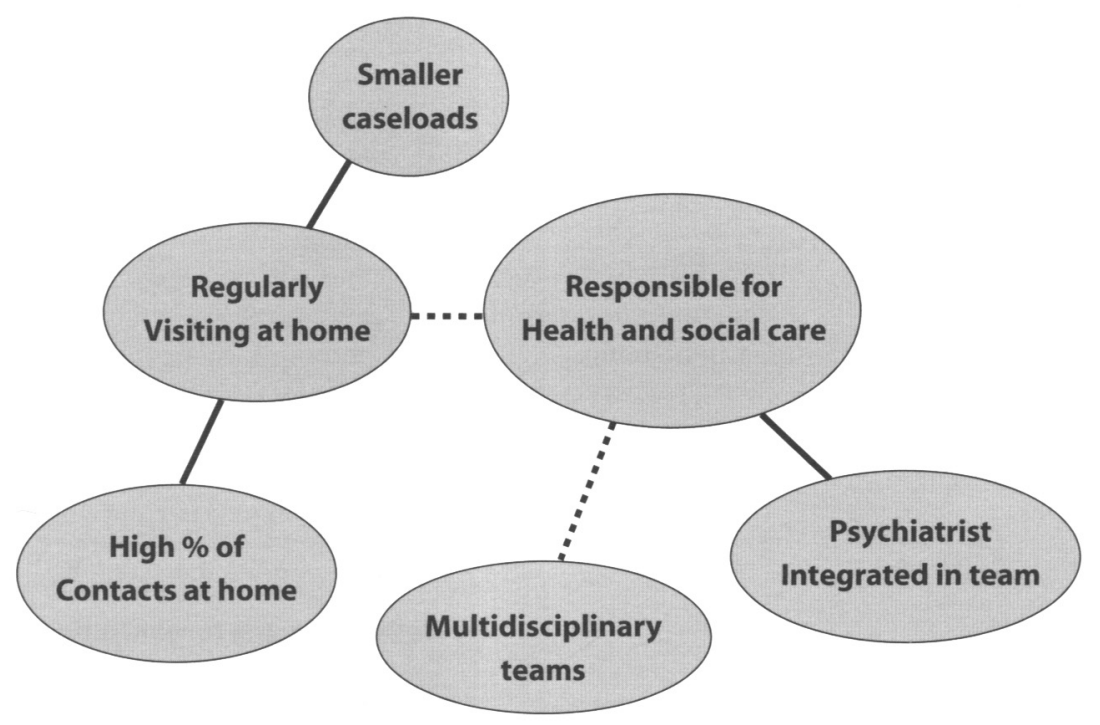

Figure 1. - Associations between service components (Wright et al., 2004).

\section{TRANSCENDING LABELS: WHAT MAKES A DIFFERENCE?}

The level of variation in clinical practice of Assertive Outreach Teams is graphically demonstrated by the examination of recently established teams in London (Wright et al., 2003). Despite strict prescription of the service model there were three distinct models of practice operating within a few years of their establishment. If ACT teams could vary this much so could CM teams; there could easily be considerable overlap in $\mathrm{CM}$ and ACT practice.

Heterogeneity in outcomes for ACT has generally been considered a problem to be overcome - explained away in terms of model fidelity or research design flaws (Gournay \& Thornicroft, 2000; Marshall et al., 1999). However it also presents an opportunity to identify effective ingredients of care empirically rather than theoretically. Using meta-regression analysis it is possible to improve on the statistical power of traditional meta- analyses by including studies with skewed outcome data and also disaggregating multi-site studies. A metaregression analysis of ICM studies (including both ACT and $\mathrm{CM}$ trials) was conducted against reduction in inpatient care (Burns et al., 2007a) and the sources of heterogeneity explored. This confirmed two major factors in determining outcome differences. The most powerful explanation of difference in outcome was found to be baseline bed usage. Recent European trials had failed to find large reductions in inpatient care not because of differences in practice but because they were conducted in the context of established tight bed management. The second explanation did however shed some light on practice differences.

Model fidelity was assessed retrospectively for each site using published data from the studies supplemented by extra data from the researchers. Using these data the organization and the staffing factor subscales of IFACT (McGrew et al., 1994) could be calculated for each site and this was regressed against the difference in inpatient 
days. Figures 2 and 3 show that the organizational features of ICM (e.g. multidisciplinary working, regular review meetings, home-based practice) were positively associated with reduction in inpatient care but the staffing features (e.g. very small caseloads, team size, professional make up of the team) were not.

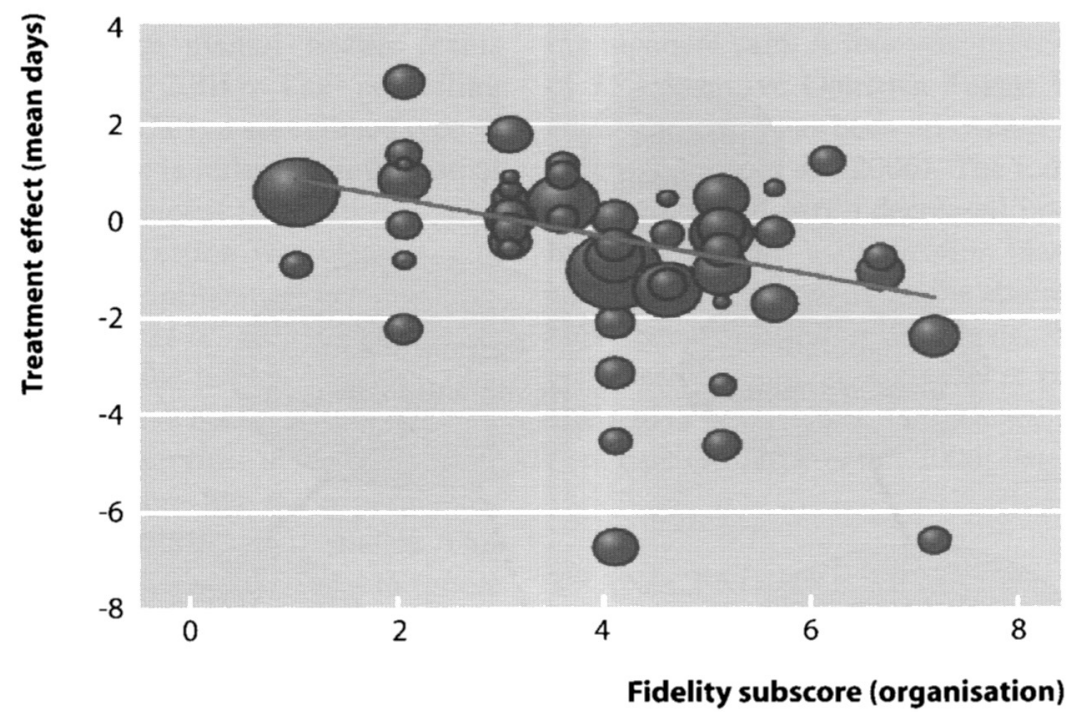

Figure 2. - Scatter plot of IFACT organisation subscore v mean days per month in hospital. Each circle is proportional to size of centre it represents. Negative treatment effect indicates that intensive case management achieved reduction in mean days in hospital relative to control (Burns et al., 2007a).

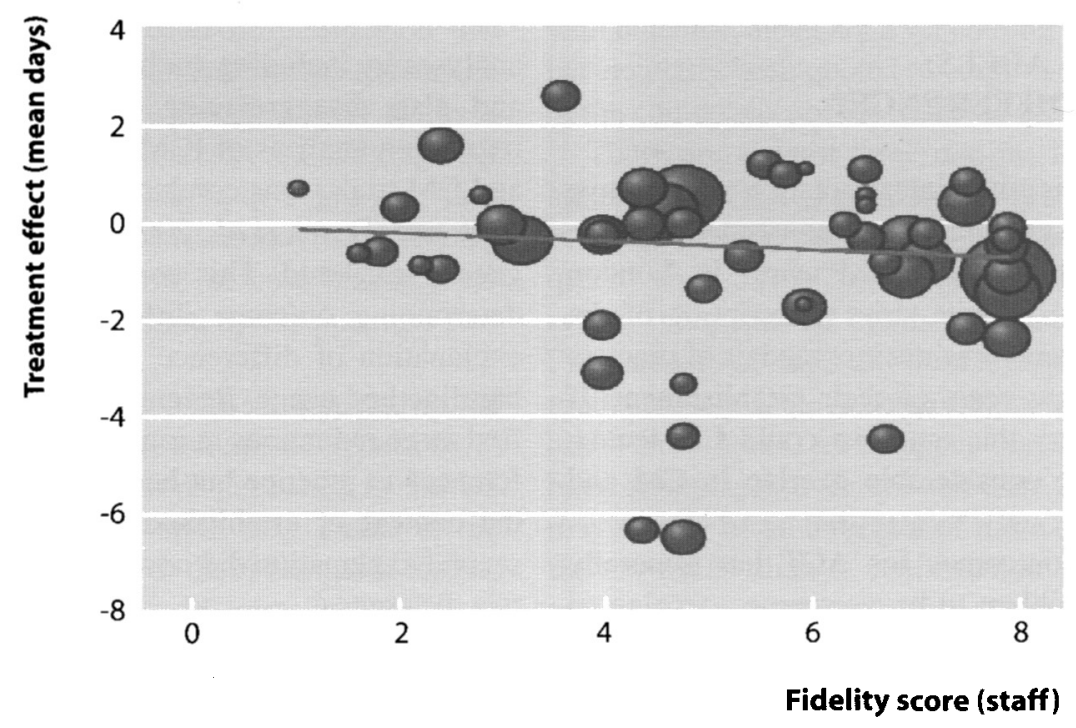

Figure 3. - Scatter plot of IFACT team membership subscore $v$ mean days per month in hospital. Each circle is proportional to size of centre it represents. Negative treatment effect indicates that intensive case management achieved reduction in mean days in hospital relative to control (Burns et al., 2007a). 


\section{ALL OR NOTHING}

A persistent criticism of research comparing ACT and CM is that ACT is 'all or nothing'; the whole is markedly superior to the sum of the parts. In short the approach generates a style of work that is qualitatively different, not just differences in degree. Self-evidently this is difficult to investigate. For instance some proponents argue that a 'whole team' approach is core to ACT. At its purest enthusiasts insist that there should be absolutely no special therapeutic relationships - patients receive visits from whoever is available that day and rarely know who is going to arrive. This avoids 'pathological dependency' and consolidates team practice. Such purist teams are hard to find; most interpret the whole-team approach loosely to indicate a multidisciplinary working where several team members work with most patients although there may still be an identified 'key-worker'.

A strongly voiced criticism of the UK700 trial was that the caseload size (1:12 or 1:15 in the ICM group ver- sus $1: 25$ or $1: 30$ in the SCM group) was above the 'threshold' of 1:10 prescribed in ACT manuals (Stein \& Santos, 1998). This is a difficult proposition to test rigorously - it would hardly be possible to conduct a series of large RCTs with varying caseload sizes to detect where the 'all or nothing' change occurred. In the UK700 trial the one site with 1:12 did not differ in outcome from those with 1:15 attributed to both being above the critical threshold. This has been explored, albeit in a relatively weak and roundabout way (Burns et al., 2007b). Using prospective data from one UK700 site, 'indicative' caseloads were calculated from contact frequencies and then compared to a proxy for a qualitative change in practice. The proxy chosen was the proportion of 'non-medical' contacts to 'medical' contacts. Figure 4 shows some suggestion that this ratio does begin to change when caseloads get below 1:20. Unfortunately the data could not support investigation below 1:10. However the findings support a dose response more than a threshold effect for caseload size.

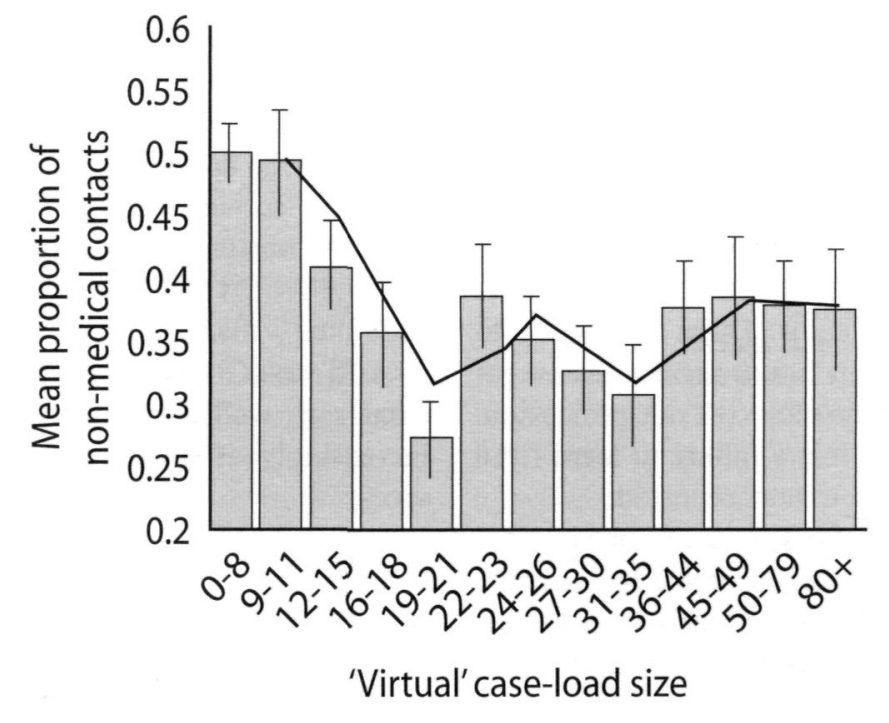

BRITISH JOURNAL OF PSYCHIATRY (2007), 190, 217-222

Figure 4. - Mean proportion of non-medical contacts according to 'virtual' case-load size. The trendline represents a moving average across the two previous bars.

\section{TREATMENTS}

One consequence of this concentration on service structures and teams is that it is common to refer to the team as if it were, in itself, an effective agent - 'ACT teams reduce hospitalisation', 'ACT results in improved social stability and reduced psychotic symptoms' etc. It is often lost sight of in this debate that no team (nor any day hospital, nor any ward) ever got a patient well. It is the effective treatments that are delivered within those struc- 
tures that make a difference. If ACT teams do reduce admissions and psychotic symptoms the question should be how? Stein and Test openly attributed this to improved medication compliance in their 1980 paper. The UK700 outcome paper concluded with a call for more attention to treatments than structures. Establishing and stabilizing resistant schizophrenia patients on clozapine is generally acknowledged as one of the obvious strengths of ACT. Future research needs to focus more on linkages between service structures, treatments provided and outcomes. $\mathrm{ACT} / \mathrm{CM}$ research may have something to learn from primary care research where process outcomes (particularly those which are evidence based interventions with established efficacy) are often used rather than individual patient rated outcomes (Kendrick et al., 1995).

Whether an ACT team or a routine CM team can deliver individual interventions will vary dependent on their culture, staffing and local circumstances. Shifting the focus from service structures to interventions may support a more flexible and efficient use of resources and allow for local initiative in a way that imposed structures do not.

\section{BROADER LESSONS FROM THE ACT VERSUS CM DEBATE}

The ACT versus CM debate appears to be cooling as the focus moves on (in the UK certainly) towards crisis teams and early intervention teams. There are lessons to learn from it that could inform future service investigations and also lessons about the nature of our profession. There are already some signs that a failure to learn from some of these mistakes may see them repeated.

The understandable desire of psychiatry to be accepted as just another branch of scientific medicine has resulted in a naïve and misleading adoption of the canon of evidence based medicine without adequate attention to what is different about psychiatry. The hierarchy of evidence from case control studies to the peak of RCTs and metaanalyses both ignores the complexity of the interventions and assumes that controls are either placebos or, at the very least, consistent and guaranteed comparators. This is clearly not the case. Control services ('TAU' - 'Treatment as Usual', 'Standard Care' etc.) vary as much, if not more, than experimental services. Judging the relevance of any specific study for local application will depend on the similarity of the study control to local practice to assess potential benefits of the experimental service. Despite early calls (Burns \& Priebe, 1996) for descriptions of controls in published papers little has changed.
Remarkable and perverse conclusions have also been drawn, using this evidence hierarchy, resulting from the prominence of interventions that can easily be examined rather than those which are generally considered essential. Examples of this are the status of acute day hospitals in the care of schizophrenia (Marshall, 2003) or the dismissal of the benefits of depot antipsychotics (Adams $e t$ al., 2001). Few clinicians would alter their practice on the basis of these findings.

Lastly it may be worth considering just why the relatively ambiguous evidence on ACT and CM achieved such powerful policy backing whereas specific treatments with overwhelming and consistent evidence (e.g. clozapine) are left to clinicians to decide on. This recent period of dramatic service configuration has accompanied a profound shift in power between clinicians and commissioners. Governments can change service structures where they may find it difficult to impose change in an individual's practice. It is difficult not to notice that there has been a shift in power during this process. Guidelines and instructions are now accepted by clinicians in a way that would have been unimaginable two decades ago (even when the evidence is against them as it was with the change from sector CMHTs to AO teams in the UK). Similarly there is some suggestion of a shift in self image among psychiatrists from a personal physician to a 'service manager'. While there may be divided opinions on the merits of these changes it does appear that the ACT/CM chapter in community psychiatry has been their vehicle.

ACT and CM can teach us about ourselves as professionals as well as about how to research and develop increasingly effective and humane mental health services.

\section{REFERENCES}

Adams C. E., Fenton M.K., Quraishi S. \& David A.S. (2001). Systematic meta-review of depot antipsychotic drugs for people with schizophrenia. British Journal of Psychiatry 179, 290-299.

Burns T. (1996). Case management: two nations still divided. Psychiatric Services 47, 793.

Burns T. \& Priebe S. (1996). Mental health care systems and their characteristics: a proposal. Acta Psychiatrica Scandinavica. 94. 381-385.

Burns T., Creed F., Fahy T., Thompson S., Tyrer P. \& White I. (1999). Intensive versus standard case management for severe psychotic illness: a randomised trial. Lancet 353, 2185-2189.

Burns T., Fioritti A., Holloway F., Malm U. \& Rossler W. (2001). Case management and assertive community treatment in Europe. Psychiatric Services 52, 631-636.

Burns T., Catty J., Dash M., Roberts C., Lockwood A. \& Marshall M (2007a). Use of intensive case management to reduce time in hospital in people with severe mental iliness: systematic review and metaregression. British Medical Joumal 335 (7615), 336. 
Burns T., Yiend J., Doll H., Fahy T., Fiander M. \& Tyrer P. (2007b). Using activity data to explore the influence of case-load size on care patterns. British Journal of Psychiatry 190, 217-222.

Catty J., Burns T., Knapp M., Watt H., Wright C., Henderson J. \& Healey A. (2002). Home treatment for mental health problems: A systematic review. Psychological Medicine 32, 383-401.

Coid J. (1994). Failure in community care: psychiatry's dilemma. British Medical Journal 308, 805-806.

Department of Health (2001). The Mental Health Policy Implementation Guide. Department of Health: London.

Drake R.E., McHugo G.J., Clark R.E., Teague G.B., Xie H., Miles K. \& Ackerson T.H. (1998). Assertive community treatment for patients with co-occurring severe mental illness and substance use disorder: A Clinical Trial. American Journal of Orthopsychiatry 68, 201-215.

Fiander M., Burns T., McHugo G.J. \& Drake R.E. (2003). Assertive community treatment across the Atlantic: comparison of model fidelity in the UK and USA. British Journal of Psychiatry 182, 248254.

Glover G., Arts G. \& Babu K.S. (2006). Crisis resolution/home treatment teams and psychiatric admission rates in England. British Journal of Psychiatry 189, 441-445.

Gournay K. \& Thornicroft G. (2000). Comments on the UK700 case management trial. British Journal of Psychiatry 370, 370-372.

Holloway F., Oliver N., Collins E. \& Carson J. (1995). Case management: a critical review of the outcome literature. European Psychiatry 10, 113-128.

Hoult J., Rosen A. \& Reynolds I. (1984).Community orientated treatment compared to psychiatric hospital orientated treatment. Social Science \& Medicine 18, 1005-1010.

Intagliata J. (1982). Improving the quality of community care for the chronically mentally disabled: the role of case management. Schizophrenia Bulletin 8, 655-674.

Kendrick T., Burns T. \& Freeling P. (1995). Randomised controlled trial of teaching general practitioners to carry out structured assessments of their long-term mentally ill patients. British Medical Journal 311, 93-98.

Killaspy H., Bebbington P., Blizard R., Johnson S., Nolan F., Pilling S. \& King M. (2006). The REACT study: randomised evaluation of assertive community treatment in north London. British Medical Journal 332, 815-820.

Marshall M. (2003). Acute psychiatric day hospitals. British Medical Journal 327, 116-117.
Marshall M. \& Lockwood A. (1998). Assertive Community Treatment for people with severe mental disorders (Cochrane Review). Cochrane Library Issue 3.

Marshall M., Bond G., Stein L.I., Shepherd G., McGrew J., Hoult J., Rosen A., Huxley P., Diamond R.J., Warner R., Olsen M., Latimer E., Goering P., Craig T.K.J., Meisler N. \& Test M.A. (1999). PRiSM Psychosis Study: Design limitations, questionable conclusions. British Journal of Psychiatry 175, 501-503.

Marshall M., Gray A., Lockwood A. \& Green R. (2001). Case management for severe mental disorders (Cochrane Review). Cochrane Library Issue 1

McGrew J.H., Bond G.R., Dietzen L. \& Salyers M. (1994). Measuring the fidelity of implementation of a mental health program model. Journal of Consulting \& Clinical Psychology 62, 670-678.

Petersen L., Jeppesen P., Thorup A., Abel M.B., Ohlenschlaeger J., Christensen T.O., Krarup G., Jorgensen P. \& Nordentoft M. (2005). A randomised multicentre trial of integrated versus standard treat ment for patients with a first episode of psychotic illness. British Medical Journal 331, 602.

Rosenheck R., Neale M., Leaf P.. Milstein R. \& Frisman L. (1995). Multisite experimental cost study of intensive psychiatric community care. Schizophrenia Bulletin. 21, 129-140.

Sashidharan S.P., Smyth M. \& Owen A. (1999). PRiSM Psychosis Study: Thro' a glass darkly: a distorted appraisal of community care. British Journal of Psychiatry 175, 504-507.

Stein L.I. \& Santos A.B. (1998). Assertive Community Treatment of Persons with Severe Mental Illness. WW Norton \& Company Inc: New York.

Stein L.I. \& Test M.A. (1980). Alternative to mental hospital treatment. I. Conceptual model, treatment program, and clinical evaluation. Archives of General Psychiatry 37, 392-397.

Thornicroft G., Wykes T., Holloway F., Johnson S. \& Szmukler G (1998). From efficacy to effectiveness in community mental health services. PRiSM Psychosis Study 10. British Journal of Psychiatry $173,423-427$

Wright C., Burns T., James P., Billings J., Johnson S., Muijen M., Priebe S., Ryrie I., Watts J. \& White I. (2003). Assertive outreach teams in London: models of operation. Pan-London Assertive Outreach Study, Part 1. British Journal of Psychiatry 183, 132-138.

Wright C., Catty J., Watt H. \& Burns T. (2004). A systematic review of home treatment services. Classification and sustainability. Social Psychiatry and Psychiatric Epidemiology 39, 789-796. 